\title{
Estimation of the Undervaluation of the Chinese Currency by a Non-linear Model
}

\author{
Gene Hsin Chang ${ }^{a^{*}}$
}

${ }^{a}$ Shanghai University of Finance and Economics and University of Toledo

\begin{abstract}
This paper conducts a quantitative estimation for the equilibrium value of the Chinese currency, the RMB, by a non-linear model, after control of the Balassa-Samuelson effect. The model provides a better fit for the valuation of the Chinese currency than the conventional linear or log linear Rogoff models. The model regression is robust. Our regression reveals that the RMB was undervalued by $32 \%$ in 2004 , but further increased to $35.8 \%$ in 2005 because the BalassaSamuelson effect diminishes as China's economy surges. These figures suggest that the extent of undervaluation of RMB is more substantial than most previous estimates, which range from $15 \%$ to $27.5 \%$. The estimates of the model provide important information about the likely changes in the value of the RMB in the near future.
\end{abstract}

JEL Classification: F31, C31

Keywords: China, currency value, exchange rate, estimation

\section{Introduction}

The equilibrium value of the Chinese currency, the RMB, has become both an academic and political subject in the past several years. There have been several different estimates of the true value of RMB. Goldstein and Lardy (2003) suggest that the RMB is undervalued by 15 to $25 \%$ in 2003 . Chang and Shao (2004) estimate an undervaluation of $22.5 \%$ in 2003 by using a linear model with a control of heteroskedasticity. Frankel (2004) uses a double log linear model and found that the RMB was 36\% undervalued in 2000. The US Senate bill sponsored by Charles Schumer (Democrat-New York) and Lindsey Graham (Republican-South Carolina) in 2005 implicitly assumes that the RMB is $27.5 \%$ undervalued, thus calling for a punitive duty of the same level of $27.5 \%$ on Chinese imports.

Each of the above estimates has some shortcomings. Goldstein and Lardy (2003) give a range for possible equilibrium values of yuan without a rigorous model or details on how they obtained the figures. Chang and Shao (2004) and Chang (2007) use a

\footnotetext{
*Email: genechang@bex.net. Tel (US): 14198439622 or 4198439181 . The author would like to thank Bill Kosteas, Haizhou Huang, anonymous referees and others for their valuable comments.
} 
linear model, but the actual relationship of the regression model seems to be non-linear. Frankel (2004) uses a log linear model, called the Rogoff model. The model regresses the log real exchange rate (RER) on the log per capita income. However, as we will show, estimates from the Rogoff model turn out to be even worse than those from a simple linear model.

In this paper I will suggest a new non-linear model for regression that fits the distribution of the observations better than either the linear or the Rogoff models. In the following section, I will discuss the data, set up the regression model, provide the estimates, and discuss the results. Section 3 concludes.

\section{Model and Estimation}

There are three basic approaches conventionally used to estimate the equilibrium value of a currency. The first is based on the supply and demand of the foreign exchanges. This type of study focuses on the trade and current account surpluses or deficits to figure out the equilibrium value of the currency. The result from this approach is, at best, the short-run market equilibrium value of the currency. This short-run value is different from the long-run equilibrium value, which is what the currency value is supposed to converge towards. The second approach is to estimate the changes in relative purchasing power parity (PPP). The problem with this approach is that the researcher must start with a benchmark year, which is usually assumed to be a time period in which the exchange rate is in equilibrium. This approach cannot be used to estimate the Chinese currency value, because China has never been in a market system in the past, and there are no such benchmark years for an equilibrium exchange rate.

The third approach is using the absolute PPP. This is more reliable and less controversial. Fewer studies in the past adopted this approach because the data for absolute PPP were more difficult to obtain than the data needed for calculating relative PPP. However, the data are now readily available. The World Development Indicator by the World Bank publishes both the GDP figures in exchange rate and the GDP figures in PPP for different countries. The implicit PPP can be derived from the difference between the two figures.

The US dollar is used as the international currency unit, and thus the common denominator. We let $e$ stand for the nominal exchange rate of a country's (including China's) currency for a dollar, that is, the country's own currency price of a US dollar. We let $p$ stand for the country's domestic price level, and $p^{*}$ for the US price level. The real exchange rate (RER) of the country's currency is RER $=\frac{e p^{*}}{p}$. In a frictionless PPP economic world with equal productivity across all sectors within each country, the real exchange rates of all countries would be the same. However, the BalassaSamuelson effect argues that the difference in productivity between rich and poor countries in the tradable sector may be large, but the difference is much smaller in the non-tradable sector; hence, the RER would be higher in poorer countries. ${ }^{1}$ In other words, currencies in the poorer countries tend to be undervalued unless we correct the

\footnotetext{
${ }^{1}$ See Samuelson (1964). Scholars often consider that the income level, or GDP per capita, is used as the proxy for the total factor productivity in the Balassa-Samuelson theory.
} 
raw data by removing the Balassa-Samuelson effect. To estimate the equilibrium value of a currency, one should take into account the Balassa-Samuelson effect. A common practice to remove the Balassa-Samuelson effect in an empirical work is regressing the RER across all countries on per capita GDP. ${ }^{2}$ Further, as Frankel (2004) suggested, the deviation from this regression line reflects the currency's over- or undervaluation. The implied argument for this approach is that, for countries which are engaged in trade, it cannot be a case that all currencies are overvalued (or all are undervalued). Frankel did not provide a theoretical model for this approach; however, to respond to a question raised by an anonymous referee, in the appendix of this paper I provide a simple theory, first, to justify using the mean of RERs as the equilibrium value; and secondly, to justify why the deviation of an RER from the mean measures the over- or under-valuation of an currency.

Figure 1 plots the RER against the income levels of 160 countries in 2001, which are available in the World Development Indicator. Chang (2007) and Chang and Shao (2004) adopt a linear function specification, $\operatorname{RER}_{i}=a+b \mathrm{GDPpc}_{i}=\varepsilon_{i}$, where GDPpc stands for the GDP per capita, and $\varepsilon_{i}$ the error term for country $i$. After a further control of the heteroskedasticity, Chang and Shao obtain the predicted RER at various per capita income levels. Table 1 replicates their results. It provides a comparison of the valuation of different currencies in the world.

Figure 1

Real Exchange Rate (RER) of Various Countries

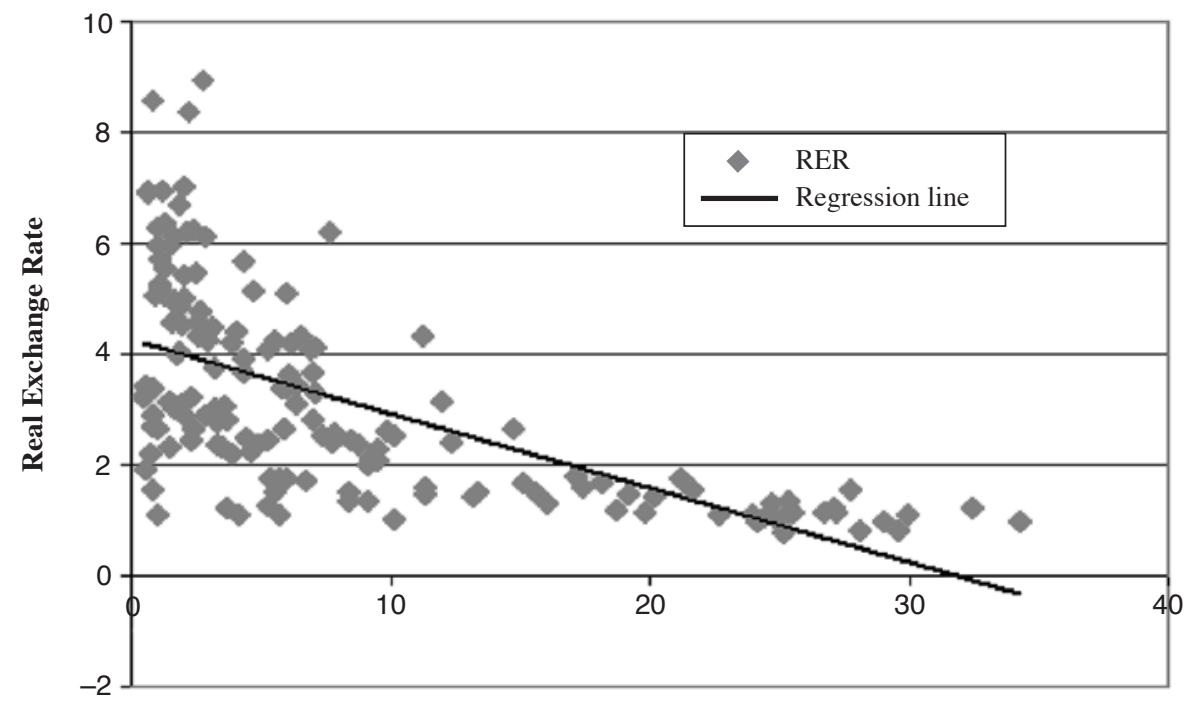

GDP per capita (1,000 US\$)

\begin{tabular}{|c|c|c|c|c|c|}
\hline & & OLS & Coefficients & Standard Error & t Stat \\
\hline Observations & 160 & Intercept & 4.28039 & 0.15922 & 26.88387 \\
\hline Sum of Square Errors & 539.8581 & GDPpc/1000 & -0.13386 & 0.01320 & -10.14495 \\
\hline
\end{tabular}

\footnotetext{
${ }^{2}$ See Rogoff (1996).
} 
Table 1

Real Exchange Rate (RER) of Selected Currencies (2001) by a Linear Regression with a Control of Heteroskedasticity

\begin{tabular}{|c|c|c|c|c|c|}
\hline Parameters & $\mathrm{a}$ & & $\mathrm{c}$ & $\mathrm{d}$ & \\
\hline Estimates & 4.15608 & -0.12034 & 1.53060 & -0.02244 & \\
\hline \multirow{2}{*}{ Country } & \multirow{2}{*}{$\begin{array}{l}\text { Per capita } \\
\text { GDP } 2001\end{array}$} & \multicolumn{2}{|c|}{ Real Exchange Rate } & \multirow{2}{*}{$\begin{array}{c}\text { Over(+) } \\
\text { Under(-) } \\
\text { valued }\end{array}$} & \multirow{2}{*}{ P-value } \\
\hline & & Actual & Predicted & & \\
\hline Kyrgyz Republic & 2750 & 8.92 & 3.83 & $-133.2 \%$ & 0.000 \\
\hline Belarus & 7620 & 6.22 & 3.24 & $-91.9 \%$ & 0.014 \\
\hline Cambodia & 1860 & 6.70 & 3.93 & $-70.3 \%$ & 0.032 \\
\hline Congo, Dem. Rep. & 680 & 6.91 & 4.07 & $-69.6 \%$ & 0.031 \\
\hline India & 2840 & 6.14 & 3.81 & $-60.9 \%$ & 0.057 \\
\hline Ukraine & 4350 & 5.68 & 3.63 & $-56.3 \%$ & 0.077 \\
\hline South Africa & 11290 & 4.31 & 2.80 & $-54.1 \%$ & 0.118 \\
\hline Vietnam & 2070 & 5.03 & 3.91 & $-28.6 \%$ & 0.225 \\
\hline Bulgaria & 6890 & 4.08 & 3.33 & $-22.6 \%$ & 0.293 \\
\hline China & 4020 & 4.41 & 3.67 & $-20.1 \%$ & 0.304 \\
\hline Bangladesh & 1610 & 4.58 & 3.96 & $-15.7 \%$ & 0.339 \\
\hline Philippines & 3840 & 4.21 & 3.69 & $-14.1 \%$ & 0.359 \\
\hline Indonesia & 2940 & 4.23 & 3.80 & $-11.3 \%$ & 0.384 \\
\hline Italy & 24670 & 1.31 & 1.19 & $-10.6 \%$ & 0.449 \\
\hline Thailand & 6400 & 3.42 & 3.39 & $-0.9 \%$ & 0.491 \\
\hline Russian Federation & 7100 & 3.32 & 3.30 & $-0.4 \%$ & 0.496 \\
\hline Hungary & 12340 & 2.42 & 2.67 & $9.4 \%$ & 0.421 \\
\hline Hong Kong, China & 24850 & 1.03 & 1.17 & $11.5 \%$ & 0.445 \\
\hline Finland & 24430 & 1.05 & 1.22 & $13.8 \%$ & 0.432 \\
\hline France & 23990 & 1.08 & 1.27 & $14.6 \%$ & 0.426 \\
\hline Sweden & 24180 & 1.03 & 1.25 & $17.8 \%$ & 0.411 \\
\hline United Kingdom & 24160 & 1.00 & 1.25 & $20.1 \%$ & 0.400 \\
\hline Korea, Rep. & 15090 & 1.69 & 2.34 & $27.7 \%$ & 0.293 \\
\hline Japan & 25130 & 0.77 & 1.13 & $31.9 \%$ & 0.354 \\
\hline Kuwait & 18700 & 1.17 & 1.91 & $38.9 \%$ & 0.253 \\
\hline Saudi Arabia & 13330 & 1.53 & 2.55 & $40.1 \%$ & 0.203 \\
\hline Zambia & 780 & 2.19 & 4.06 & $46.0 \%$ & 0.109 \\
\hline Venezuela, RB & 5670 & 1.12 & 3.47 & $67.9 \%$ & 0.047 \\
\hline Congo, Rep. & 970 & 1.10 & 4.04 & $72.8 \%$ & 0.026 \\
\hline
\end{tabular}

Note: This table replicates Table 1 of Chang and Shao (2004). The data was from WDI online 2003, hence the actual RER for China is slightly different from the other tables which are based on the WDI online 2006.

Figure 1 plots the 160 observations in the sample with the linear fitted line. One can see from Figure 1 that the relationship between RER and income is not linear, but rather, 
a non-linear curve. Frankel (2004) adopts a double log form specification suggested by Rogoff: In $\mathrm{RER}_{i}=a+b \ln \mathrm{GDPpc}_{i}+\varepsilon_{i}$ to estimate the undervaluation of RMB. Figure 2 shows the curve from the regression and the observations. While the Rogoff specification is non-linear, it does not seem to be a better fit than the linear curve. The regression results appear to be out of line. For instance, it says that in 2003, China's currency RMB is $196 \%$ undervalued. The second last column of Table 3 from the right shows all of the estimation results from the Rogoff model.

Figure 2

Fitted Regression Line by the Rogoff Specification

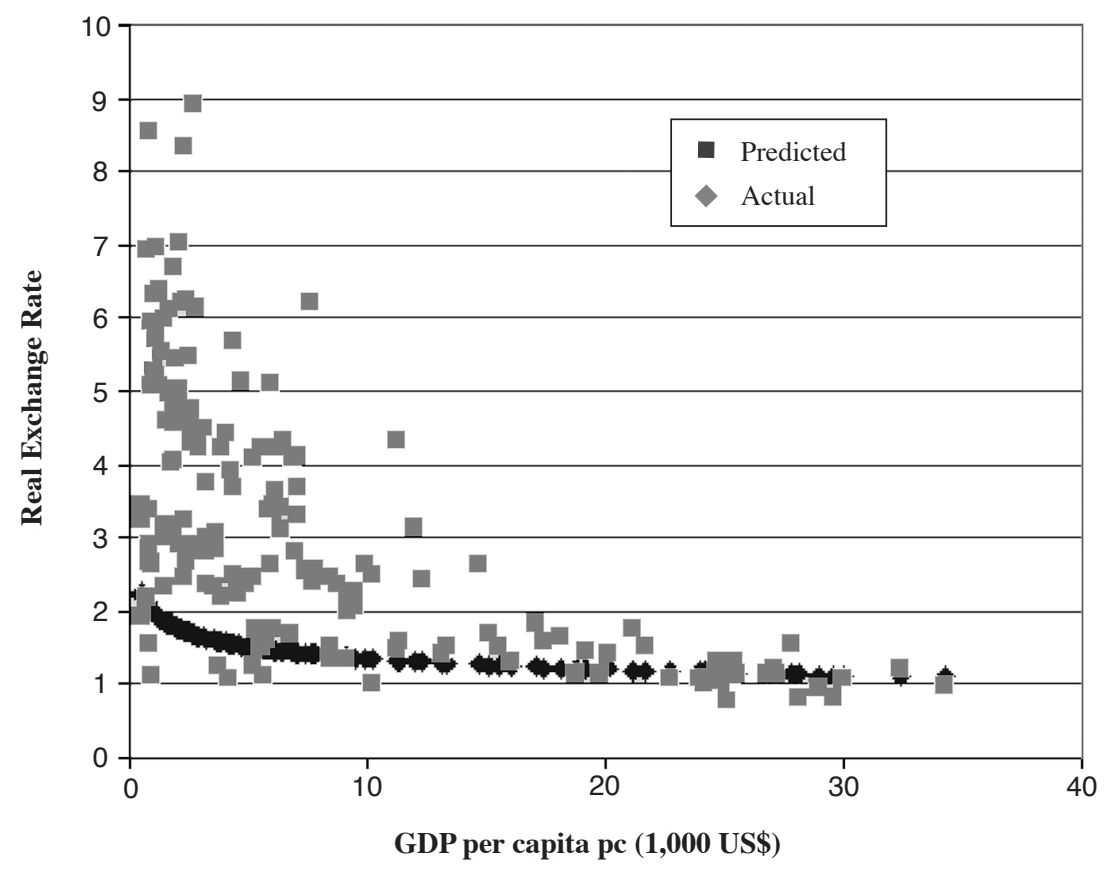

Regression Function: $\log$ RER $=\mathrm{a}+\mathrm{b} \log$ GDPpc/1000

Observation: 160

Coefficients a b

$0.68742-0.38561$

Sum of Squared Errors of the log RER values: $\quad 11.105$

Sum of Squared Errors of the true values*: $\quad 856.44$

*Note: To obtain this value, we first recover the predicted true value of RER, then obtain the sum of squared errors between the actual and true predicted values of RER.

In this study, I suggest a new specification for the relationship between RER and per capita income level as follows:

$$
\mathrm{RER}_{i}=c+\left(a+b \mathrm{GDPpc}_{i}\right)^{-1}+\varepsilon_{i}
$$

The equation is relatively simple with only three coefficients to be estimated. The error term $\varepsilon_{i}$ is assumed to be independently and normally distributed. So the Maximum 
Likelihood Estimation (MLE) maximization provides consistent estimates, even if heteroskedasticity exists. The model is quite robust in searching for the optimal values of the coefficients by MLE from various initial values. At the same time, it also fits the distribution of the RER data very well.

To estimate, we use the sample in Chang and Shao (2004), which includes only the country data from 2001 provided by the World Bank. ${ }^{3}$ This sample still consists of 160 observations, which is large enough for meaningful estimation. Because we use only data from 2001, we avoid adding dummy variables for the possible structural shifts over time periods. We use the MLE method to obtain consistent estimates for the coefficients $a, b$ and $c$. Then we use the estimates to obtain the predicted values, which leads to the regression curve. Figure 3 plots the regression curve along with the original observations. The coefficient estimates of the regression are listed at the table at the bottom of Figure 3.

Figure 3

The New Regression Model

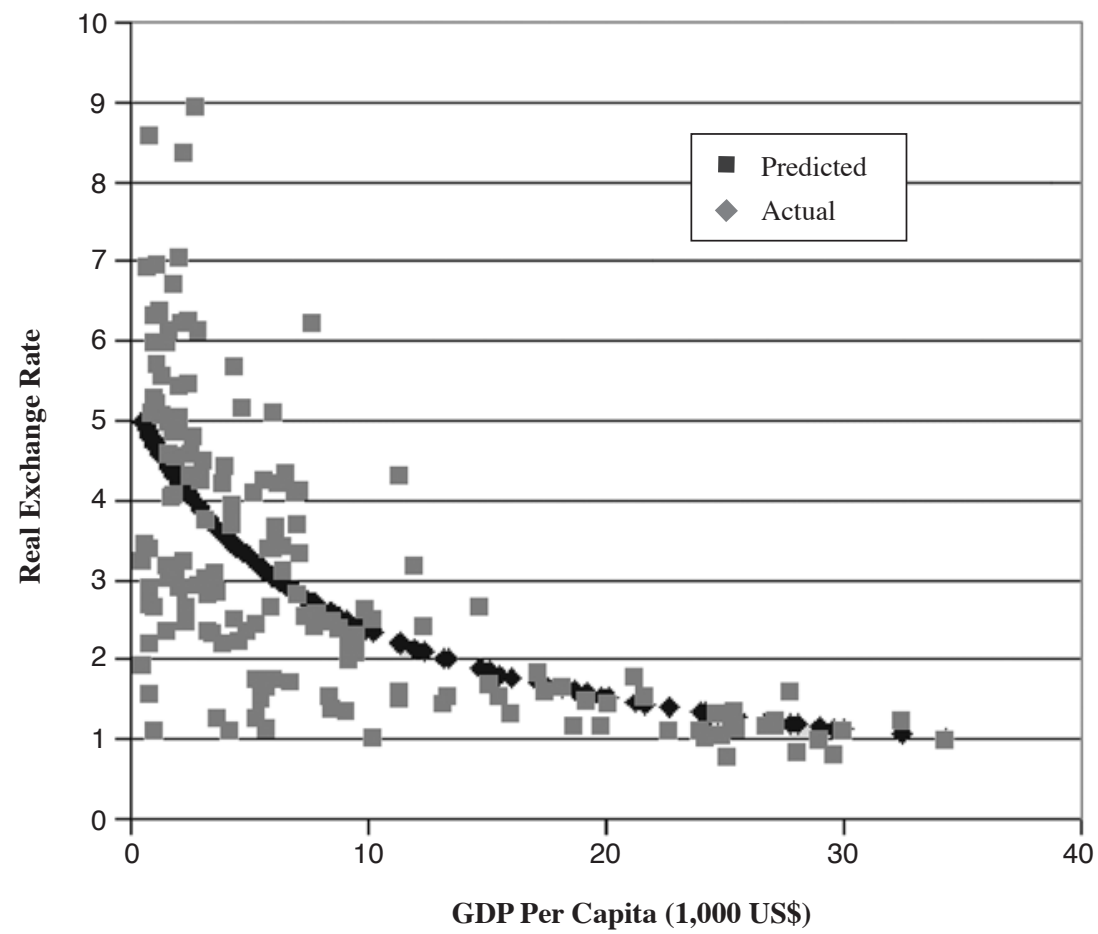

Regression function: $\quad \operatorname{RER}=\mathrm{c}+(\mathrm{a}+\mathrm{b} \operatorname{GDPpc} / 1000)^{\wedge}(-1)+\varepsilon$

\begin{tabular}{lcccc}
\hline Observations & 160 & & Sum of squared errors: & 299.0869 \\
\hline Estimated coefficients & $\mathrm{a}$ & $\mathrm{b}$ & $\mathrm{c}$ & \\
\hline & 0.18903852 & 0.023503552 & 0.010 \\
\hline
\end{tabular}

\footnotetext{
${ }^{3}$ WDI online, Oct. 2003, the World Bank
} 
We use the Quasi-Newton algorithm to do the MLE optimization. The model is robust in various initial values. In optimization, I set the non-negative bounds for the three estimates. In theory, the coefficient $c$ is supposed to be around 1 . That is, the RER is supposed to be 1 when GDPpc is approaching infinity. However, the regression results measured by SSE turn out to be worse when the low bound is set to 1 than when the low bound is set to less than 1. After several trials, the lower bound is set to 0.1. The SSE does not improve noticeably beyond this level.

The fit by the regression turns out to be quite good with this setup of restrictions. From Figure 3, one can see that the proposed function approaches 1 at an income level of about US $\$ 40,000$, which is the upper limit of the GDP per capita in the current world. This implies that the proposed function is powerful, but may be limited to a certain range of income levels (say, below the US\$40,000 GDP per capita level). A further refinement of the function beyond the per capita income level of US $\$ 40,000$ can be a piecewise function that consists of another function when income is beyond US\$40,000. Yet this is beyond the income range we are concerned with here.

From a comparison among the three figures, one can see that the new specification provides a better fit to the distribution of the observation. This is indeed proved to be the case when we compare the sum of squared errors (SSE) of the three regressions. The Rogoff double log model is the worst, with a value of SSE of 856.44. The straight linear model has the value of SSE of 539.86. The new non-linear model reduces the SSE to 299.07. Apparently, the new specification in this study offers a better description of the relationship between RER and the per capita income level.

We then use the estimated model to obtain the predicted RER for China by the estimated coefficients, which are shown in Table 2. The last column of Table 2 present the estimated overvaluation (+) or undervaluation (-) of RMB.

Table 2

Real Exchange Rate of China

\begin{tabular}{ccccc} 
& Per capita & \multicolumn{2}{c}{ Real Exchange Rate } & \begin{tabular}{c} 
Over(+) \\
Under(-) \\
\cline { 3 - 4 } Year
\end{tabular} \\
\cline { 3 - 4 } GDP 2001 & Actual & Predicted & $74.0 \%$ \\
\hline 1975 & 585 & 1.28 & 4.94 & $71.3 \%$ \\
1976 & 567 & 1.42 & 4.95 & $71.0 \%$ \\
1977 & 601 & 1.43 & 4.93 & $59.2 \%$ \\
1978 & 662 & 2.00 & 4.90 & $59.8 \%$ \\
1979 & 704 & 1.96 & 4.87 & $55.8 \%$ \\
1980 & 749 & 2.15 & 4.85 & $50.1 \%$ \\
1981 & 779 & 2.41 & 4.83 & $44.6 \%$ \\
1982 & 835 & 2.66 & 4.80 & $42.9 \%$ \\
1983 & 911 & 2.72 & 4.76 & $38.7 \%$ \\
1984 & 1035 & 2.88 & 4.70 & $38.8 \%$ \\
1985 & 1161 & 2.84 & 4.63 & $28.9 \%$ \\
1986 & 1248 & 3.26 & 4.59 & $8.9 \%$ \\
1987 & 1371 & 4.13 & 4.53 & $7.2 \%$ \\
1988 & 1502 & 4.15 & 4.47 &
\end{tabular}




\begin{tabular}{ccccc}
1989 & 1538 & 4.02 & 4.45 & $9.7 \%$ \\
1990 & 1570 & 4.17 & 4.44 & $6.0 \%$ \\
1991 & 1692 & 4.44 & 4.38 & $-1.4 \%$ \\
1992 & 1912 & 4.68 & 4.28 & $-9.3 \%$ \\
1993 & 2151 & 5.28 & 4.18 & $-26.1 \%$ \\
1994 & 2394 & 4.83 & 4.09 & $-18.1 \%$ \\
1995 & 2656 & 4.28 & 3.99 & $-7.4 \%$ \\
1996 & 2876 & 4.09 & 3.91 & $-4.8 \%$ \\
1997 & 3088 & 4.10 & 3.83 & $-7.1 \%$ \\
1998 & 3315 & 4.27 & 3.76 & $-13.7 \%$ \\
1999 & 3506 & 4.41 & 3.69 & $-19.5 \%$ \\
2000 & 3756 & 4.46 & 3.62 & $-23.5 \%$ \\
2001 & 4020 & 4.53 & 3.54 & $-28.0 \%$ \\
2002 & 4305 & 4.59 & 3.46 & $-32.7 \%$ \\
2003 & 4647 & 4.55 & 3.36 & $-35.3 \%$ \\
2004 & 4999 & 4.32 & 3.27 & $-32.0 \%$ \\
$2005^{*}$ & 5462 & 4.29 & 3.16 & $-35.8 \%$ \\
\hline
\end{tabular}

* estimates

Sources of data: For period from 1975-2003, from WDI on line, April 2006

Data after 2003 are adjusted by using the updated information from Chinese Statistical Bureau Website Database.

It can be seen that RMB had been overvalued prior to 1991, but has been undervalued since that year. The undervaluation has become more substantial since the beginning of this century. The undervaluation of the RMB against the dollar reached $35.3 \%$ in 2003 and $32.0 \%$ in 2004. What is interesting is that in 2005 the undervaluation increased to $35.8 \%$, although the Chinese authority revalued the nominal exchange rate by more than $2 \%$ in 2005. During 2005 China's GDP inflation rate is $3.7 \%$, slightly higher than that in the US (3.1\%). Adding the nominal revaluation, the Chinese currency actually had a real revaluation in 2005. The reason the undervaluation even increased during the same year is because the rapid growth in China caused the BalassaSamuelson effect to diminish in our regression model.

During the past four years, the US and many other countries have pressed China to revalue its currency whenever a trade dispute arose with China. Our empirical test reveals that, regardless of whether or not the revaluation would help reduce their trade deficits with China, the argument that the RMB was undervalued is valid. While our estimates support the argument that the Chinese currency is undervalued, the figures need to be interpreted with caution. The estimates are subject to all possible random errors from the data sample and other possible statistical problems.

To make a comparison of the empirical results from different models, Table 3 presents the estimates for the undervaluation of RMB from four different models in one table. The Rogoff double log model does not provide convincing results, as it shows that the RMB has been undervalued by more than $100 \%$ since 1987 . This result is different from the other three models. The results of the OLS linear model and that of 
the linear model with a control of heteroskedasticity are consistent among themselves. The new non-linear model is also in line with the linear models in terms of the trend of the changes in the valuation of RMB, although the numerical values are quite different in some years. Overall, these figures of the three models (except the Rogoff model) provide some consistent information about the state of RMB valuation.

Table 3

Comparison of the Estimates of Undervaluation from Various Models

Linear

\begin{tabular}{|c|c|c|c|c|}
\hline Year & OLS & $\begin{array}{c}\text { control of } \\
\text { heteroskedasticity }\end{array}$ & $\begin{array}{c}\text { Rogoff } \\
\text { Log model }\end{array}$ & $\begin{array}{l}\text { New non- } \\
\text { linear model }\end{array}$ \\
\hline 1975 & $69.4 \%$ & $66.7 \%$ & $41.0 \%$ & $74.0 \%$ \\
\hline 1976 & $66.2 \%$ & $64.8 \%$ & $35.0 \%$ & $71.3 \%$ \\
\hline 1977 & $66.0 \%$ & $65.5 \%$ & $34.0 \%$ & $71.0 \%$ \\
\hline 1978 & $52.3 \%$ & $51.3 \%$ & $6.2 \%$ & $59.2 \%$ \\
\hline 1979 & $53.2 \%$ & $50.8 \%$ & $7.2 \%$ & $59.8 \%$ \\
\hline 1980 & $48.7 \%$ & $44.9 \%$ & $-2.8 \%$ & $55.8 \%$ \\
\hline 1981 & $42.3 \%$ & $40.2 \%$ & $-16.2 \%$ & $50.1 \%$ \\
\hline 1982 & $36.2 \%$ & $36.8 \%$ & $-29.7 \%$ & $44.6 \%$ \\
\hline 1983 & $34.7 \%$ & $38.5 \%$ & $-34.5 \%$ & $42.9 \%$ \\
\hline 1984 & $30.5 \%$ & $33.8 \%$ & $-45.6 \%$ & $38.7 \%$ \\
\hline 1985 & $31.3 \%$ & $33.3 \%$ & $-46.2 \%$ & $38.8 \%$ \\
\hline 1986 & $20.7 \%$ & $19.7 \%$ & $-70.2 \%$ & $28.9 \%$ \\
\hline 1987 & $-0.7 \%$ & $-8.9 \%$ & $-118.8 \%$ & $8.9 \%$ \\
\hline 1988 & $-1.6 \%$ & $-13.6 \%$ & $-123.2 \%$ & $7.2 \%$ \\
\hline 1989 & $1.4 \%$ & $-4.4 \%$ & $-117.1 \%$ & $9.7 \%$ \\
\hline 1990 & $-2.5 \%$ & $-5.0 \%$ & $-126.2 \%$ & $6.0 \%$ \\
\hline 1991 & $-9.6 \%$ & $-11.2 \%$ & $-143.9 \%$ & $-1.4 \%$ \\
\hline 1992 & $-16.3 \%$ & $-19.7 \%$ & $-162.4 \%$ & $-9.3 \%$ \\
\hline 1993 & $-32.2 \%$ & $-35.2 \%$ & $-201.7 \%$ & $-26.1 \%$ \\
\hline 1994 & $-21.9 \%$ & $-24.3 \%$ & $-181.0 \%$ & $-18.1 \%$ \\
\hline 1995 & $-9.1 \%$ & $-12.6 \%$ & $-153.6 \%$ & $-7.4 \%$ \\
\hline 1996 & $-5.1 \%$ & $-7.4 \%$ & $-145.8 \%$ & $-4.8 \%$ \\
\hline 1997 & $-6.1 \%$ & $-6.1 \%$ & $-149.3 \%$ & $-7.1 \%$ \\
\hline 1998 & $-11.3 \%$ & $-8.9 \%$ & $-162.4 \%$ & $-13.7 \%$ \\
\hline 1999 & $-15.8 \%$ & $-14.3 \%$ & $-173.9 \%$ & $-19.5 \%$ \\
\hline 2000 & $-18.2 \%$ & $-18.4 \%$ & $-180.2 \%$ & $-23.5 \%$ \\
\hline 2001 & $-21.0 \%$ & $-20.1 \%$ & $-187.5 \%$ & $-28.0 \%$ \\
\hline 2002 & $-23.8 \%$ & $-23.2 \%$ & $-194.6 \%$ & $-32.7 \%$ \\
\hline 2003 & $-24.4 \%$ & $-22.5 \%$ & $-196.0 \%$ & $-35.3 \%$ \\
\hline 2004 & $-19.6 \%$ & $-19.2 \%$ & $-184.4 \%$ & $-32.0 \%$ \\
\hline $2005 *$ & $-11.5 \%$ & & $-164.6 \%$ & $-25.3 \%$ \\
\hline
\end{tabular}




\section{Concluding Remarks}

In this paper, we suggest a non-linear specification for estimating the long-run equilibrium value of the RMB, after controlling the Balassa-Samuelson effect. Our model provides a much better fit for the data than the previous models, including the linear model and the Rogoff double log model. The Rogoff model was rejected because it fails to provide a good fit for the data and it does not provide convincing estimates about the valuation of the RMB against the US dollar or international currencies. The estimates for the valuation of the RMB from the linear model are generally consistent with the consensus about the valuation of the RMB. However, the relationship between the per capita income level and RER is apparently non-linear. Hence, the linear model does not fit the distribution of the data well, especially for those observations far away from the mean of the per capita income. Estimates for the undervaluation of RMB by our new non-linear model are generally consistent with the results of the linear models, but the results are more accurate because the non-linear model describes the implied relationship better and has a much better fit for the world data.

Our results, reported in Table 2, show that the RMB was overvalued in the 1970s and 1980s, but undervalued in the 1990s and 2000s. Admittedly, the predicted figures in 1970s and 1980s are less accurate, since the economic structure in those periods were likely different from that in 2001 , the year from which we obtained the estimated parameters. However, these predicted figures still seem to fit conventional beliefs about the dynamic changes in the RMB values. We see that the RMB was substantially overvalued prior to 1986 . In 1986 China introduced the dual track exchange rate regime, and at the beginning of 1994, China unified the exchange rates. This explains why the RER abruptly changed in those two years. After 1998, undervaluation has tended to increase. Two forces are behind this trend. First, the RER grew due to low inflation or even deflation during this period in China. Secondly, the predicted RER declined because of rapid economic growth.

Our results show that the RMB has been undervalued in the range of $25 \%$ to $36 \%$ in the past four years. This seems to confirm the general opinion of the extent of undervaluation of RMB, such as by Lardy and Goldstein or by the US Congress. In July, 2005, China announced its abandonment of the ad hoc dollar-peg exchange rate system; since then, China has allowed the RMB to adjust within a moderate range to respond to market forces. As a result, the RMB has steadily revalued. Yet, because the government still intervenes heavily, the revaluation has been very limited. The RMB revalued cumulatively only by $3.2 \%$ from the previous 8.27 yuan to one dollar in July 2005, to 8.01 yuan to one dollar in April 2006. This extent of revaluation is certainly too small to satisfy the market pressure.

What is the future of the RMB? On one hand, we can anticipate two forces that will push for a real revaluation of RMB or a reduction of the extent of undervaluation of RMB. The first force is nominal revaluation. The second force is an inflation rate in China greater than that in the US. The undervaluation of RMB will lead to a foreign capital inflow, thus causing the monetary base to increase and adding pressure to the price level. The surge in prices of new houses and construction material in China during the period of 2003 and 2004 is an example to confirm this theory. For instance, in 2005, 
the inflation rate measured by the GDP deflator in China was 3.8\%, higher than that in the US. This difference in the inflation rates has effectively revalued the RMB in real terms.

On the other hand, we also anticipate a counterforce against a real revaluation of RMB. As the Chinese economy grows and GDP per capita increases, the BalassaSamuelson effect diminishes. Hence, ceteris paribus, the estimated undervaluation of RMB by our model will intensify. The net result of the change in valuation of the RMB will depend on the relative magnitudes of these positive and negative forces. However, one can expect that market force will dominate once the RMB moves to a more flexible regime; hence, we can be confident in predicting that the revaluation of RMB is the trend for the near future.

\section{References}

Chang, G.H., 2007, "Is the Chinese Currency Undervalued? Empirical Evidence and Policy Implication", The International Journal of Public Administration 30, 137148.

Chang, G.H. and Q. Shao, 2004, "How Much Is the Chinese Currency Undervalued? A Quantitative Estimation”, China Economic Review 15, 366-371.

Frankel, J., 2004, "On the Renminbi: The Choice Between Adjustment under a Fixed Exchange Rate and Adjustment under a Flexible Rate", written for a High-level Seminar on Foreign Exchange System, Dalian, China, May 26-27, 2004. A version is available online: http://www.nber.org/papers/w11274.

Goldstein, M. and N. Lardy, 2003, "China's Exchange Rate Regime", Asian Wall Street Journal, September 12.

Rogoff, K., 1996, “The Purchasing Power Parity Puzzle”, Journal of Economic Literature 34, 647-668.

Samuelson, P.A., 1964, “Theoretical Notes on Trade Problems", Review of Economics and Statistics 46, 145-154. 


\section{Appendix}

\section{The Deviation of RERs from the Mean Measures the Extent of Over- or Under- valuation}

In what follows we provide a simple justification for using the mean value of RERs of all countries as the equilibrium value, and, the deviation from the mean is interpreted as the extent of over- or under-valuation.

Let us start with a simplified model, so we can focus on the core issue. Assume that there are $n$ countries engaged in trade, all are of the same economic size and at the same income level. Country $i$ 's trade (or, current account balance) is a function of its overvaluation or undervaluation. In particular, we set up:

$$
T_{i}=a\left(\mathrm{RER}_{i}-\mathrm{RER}^{*}\right)
$$

where $T_{i}$ is the trade balance of country $i$. RER ${ }^{*}$ is the equilibrium real exchange rate. $\mathrm{RER}_{i}$ is the real exchange rate of country $i$, and $a$ is a constant. If country $i$ 's currency is undervalued, thus $\mathrm{RER}_{i}-\mathrm{RER}^{*}>0$, then $T_{i}>0$. The country runs a trade surplus. If the country revalues its currency to return to the equilibrium level thus $\mathrm{RER}_{i}-\mathrm{RER}^{*}>$ 0 , then its trade is in balance, $T_{i}=0$. Conversely, if its trade is not balanced, its currency is not at the equilibrium level. These arguments are straightforward in international economics.

Summarize all countries trade, and note that it must be globally balanced: $\sum_{i} T_{i}=0$.
have

$$
\sum_{i}^{n} T_{i}=a \sum_{i}^{n}\left(\mathrm{RER}_{i}-\mathrm{RER}^{*}\right)=0
$$

then,

$$
\sum_{i} \mathrm{RER}_{i}=n \mathrm{RER}^{*}
$$

then we have the equilibrium real exchange rate $\mathrm{RER}^{*}$ is determined by,

$$
\mathrm{RER}^{*}=\frac{1}{n} \sum_{i} \mathrm{RER}_{i}
$$

Now we see that the equilibrium exchange rate is the mean of the real exchange rates. Further, the difference between $\mathrm{RER}_{i}$ and $\mathrm{RER}^{*}, \mathrm{RER}_{i}-\mathrm{RER}^{*}$, measures the under- or overvaluation, i.e., the "error" term measures the magnitude of the under- or overvaluation. If the error is corrected, the country will return to the trade balance state.

To take into account of the Balassa-Samuelson effect, we run regression on GDP per capita. The resulting predicted regression line is the means of the RERs of all countries at the same GDP levels. Hence, the deviation from the predicted line (regression line), that is, the residual term, measures the magnitude of under- or overvaluation of a currency, taking into account of the Balassa-Samuelson effect. 